\title{
SMART PRODUCTS AND SERVICE SYSTEMS FOR E-BUSINESS TRANSFORMATION
}

\author{
Jay Lee \\ Wisconsin Distinguished and Rockwell Automation Professor \\ and \\ Director of Center for Intelligent Maintenance Systems (IMS) \\ University of Wisconsin-Milwaukee, WI, USA \\ Phone: 414-229-5304 \\ E-mail: jaylee@uwm.edu
}

\begin{abstract}
Web-based intelligent is key to achieve global leadership in six-sigma product aftermarket service and manufacturing productivity for the 21 st century. The need to improve the understanding of product's performance for aftermarket service will lead to e-intelligence for quality maintenance and product development. With the proper integration of e-intelligence into products, manufacturing and service systems, manufacturers and users will benefit from the increased equipment and process reliability. This paper discusses how to design smart products and maintenance systems using web-based intelligence technologies. First, a brief introduction about the trends of product and maintenance innovation in industry and perspectives are given. Second, needs and focuses for future product design, manufacturing and service strategies are introduced. Finally, design of e-intelligence for smart product and its future impacts to transform six-sigma product service automation to business automation excellence are discussed.
\end{abstract}

Keywords: e-intelligence, remote monitoring, e-business, prognostics, e-maintenance

\section{INTRODUCTION}

For the past decade, the impact of web-based technologies has added 'velocity' to the design, manufacturing, and aftermarket service of a product. Today's competition in manufacturing industry depends not just on lean manufacturing, but also on the ability to provide customers with lean service and life-cycle costs for sustainable value. With emerging use and applications of internet and wireless communication technologies, the impact of e- intelligence is forcing companies to shift their manufacturing operations from the traditional factory integration philosophy to an e-factory and e-supply chain philosophy. It transforms companies from a local factory automation to a global enterprise and business automation. The technological advances for achieving this highly collaborative design and manufacturing environment is based on multimedia type information-based engineering tools and a highly reliable communication system for enabling distributed procedures in concurrent engineering design, remote operation of manufacturing processes, and operation of distributed production systems. This transition is dependent upon the advancement of next-generation manufacturing practices on " $e$-factory and e-automation" which is focused on the use of information to make things happen collaboratively on a global basis.

Quality is no longer an objective; it is a prerequisite for competing in the global marketplace. Smart companies must focus on service innovation and asset optimization for customer intimacy, not just customer satisfaction. In addition, the complexity of today's products has greatly increased consumer attention on product's life cycle cost. For example, General Electric Company's strategic transformation [Welch et al, 1996] toward an industry leader in six-sigma service in 1995 has inspired many companies to follow. Many industries, including the aerospace industry (i.e. jet engine, aircraft), the semiconductor industry (i.e. chip making companies and foundry), the power generation industry (i.e. power utilities companies), the transportation industry (i.e. trucking, airlines), the medical equipment industry, and the building system industry (i.e. elevators, HVACs), have been strategically benchmarking smart predictive maintenance and customer service practices globally to maintain their manufacturing productivity and customer's intimacy for a better competitive position. For example, the latest Pratt \& Whitney jet engines have an array of sensors and on-board diagnostics that are capable of generating information with sufficient detail to allow the ground systems to forecast repair needs months in advance. This helps the airlines schedule engine removals so that the cost of downtime is balanced against the cost of overhaul. The on-board systems, in concert with the ground based analysis capabilities, also reduce costly unscheduled events such as delays, cancellations, diversion and in-flight shutdowns.

Today's automotive industry is also looking for ways to embrace telematics for getting automatic roadside assistant and route guidance into car. GM has set a goal for its OnStar telematics service of one million subscribers by the end of 2000. By 2005, GM plans to have all of its cars equipped with the hardware and software components for OnStar with enhanced features [Telematics, 2001]. For the semiconductor manufacturing industry, one of the major thrusts is e-diagnostics. E-diagnostics is 
the ability to remotely service equipment and provide application support such as correcting chipmanufacturing errors via the internet. Chip manufacturers use remote diagnostics software instead of having an engineer come out to a site to adjust chip-making equipment. As chips get smaller, production errors rise. Moving to smaller chips can result in 10 times as many errors, even for leaders such as Intel Corp. and IBM Corp. These errors can force a chip company to shut a production line, causing it to lose thousands of dollars. This is one of the biggest problems chipmakers face today. KLA-Tencor foresees that the semiconductor industry will move toward e-diagnostics technologies for integrated diagnostics monitoring. These enabling technologies will impact the entire industry, not just semiconductor business [Schroeder, 2000]. Further advancements of these smart industrial applications will be dependent upon continuous innovation and the advancement of next-generation web-enabled intelligent systems.

Smart agents [Lee, 1999] can predict the failure of a system in advance. Such "prognostic" capabilities enable companies to achieve innovative aftermarket service to reduce or eliminate production and service downtime, and reduce dimensional variation due to performance degradation. Smart software and NetWare can provide proactive maintenance capabilities such as performance degradation measurement, fault recovery, selfmaintenance and remote diagnostics. These features would allow manufacturing industry to develop proactive maintenance strategies to guarantee the highest and continuous product quality, process performance, and ultimately eliminate unexpected system breakdowns and unnecessary periodical maintenance practices. These transformations demand intelligent maintenance technologies to change the maintenance strategy from current mean-time-between-failure (MTBF) practices to meantime-between-degradation (MTBD) technologies [Lee \& Wang, 1999]. Figure 1 illustrates the evolution of product and manufacturing innovation and the future trend from 1980s to today and future. Nowadays product focus has been changed from information and computer intelligence to knowledge and e-intelligence as need to fulfill the fickle customer demands. Manufacturing focus is shifting from factory automation to business automation to trigger the product focus. Quality focus is addressing e-service for customer solutions and asset optimization where as in the past it was mentioned as TQM and six sigma for business process as the manufacturing is not beyond the factory floor. Therefore, the changes of the business strategies are needed to stay with the competitive business, which comes from growing trend of customers demands.

\begin{tabular}{|c|c|c|c|}
\hline $\begin{array}{c}\text { Product } \\
\text { Focus }\end{array}$ & $\begin{array}{c}\text { 1980s } \\
\text { Mechatonics } \\
\text { (data \& control } \\
\text { inteligence) }\end{array}$ & $\begin{array}{c}\text { Product that Thinks and } \\
\text { Links } \\
\text { (information \& computer } \\
\text { intelligence) }\end{array}$ & $\begin{array}{c}\text { Products that Leam, Grow, } \\
\text { Reconfigure \& Sustain } \\
\text { (knowedge \& e- } \\
\text { intelligence) }\end{array}$ \\
\hline $\begin{array}{c}\text { Manufacturing } \\
\text { Focus }\end{array}$ & $\begin{array}{c}\text { Factory Automation } \\
\text { (flexibility) }\end{array}$ & $\begin{array}{c}\text { Enterprise Automation } \\
\text { (agilly) }\end{array}$ & $\begin{array}{c}\text { Business Automation } \\
\text { (velocity) }\end{array}$ \\
\hline $\begin{array}{c}\text { Quality Focus } \\
\text { SPC \& TOMFor Mfg } \\
\text { Process } \\
\text { (factory) }\end{array}$ & $\begin{array}{c}\text { Six-Sigma for Business } \\
\text { Process } \\
\text { (enterprise) }\end{array}$ & $\begin{array}{c}\text { E-service for Customer } \\
\text { Solutions \& Asset } \\
\text { Optimization } \\
\text { (customers) }\end{array}$ \\
\hline
\end{tabular}

Figure 1. Evolution on product, manufacturing and quality

\section{NEEDS FOR NEXT-GENERATION PRODUCT AND MANUFACTURING SYSTEMS}

For a manufacturing company to achieve smart business performance with integrated design, manufacturing and service system must consider e-intelligence. Nowadays the most important part of the manufacturing systems' inventory becomes the major integration information management system, the physical assets are becoming functional assets, and the product and services are becoming the customer support solution infrastructure. Today's e-business is focusing on the data transaction whereas tomorrow's e-business needs intelligence to perform transaction with predictive customer needs (as- set management), optimize the value and smart business to device innovation for customer intimacy. These new perspectives on e-Business intelligence strategies for business innovation are summarized in Figure 2.

For instance, electronics related products have become one of the largest industries in the world. Among the most challenging operations management issues in this industry is the design of electronics assembly systems, and fulfil the growing customer's requirements as the life cycle of the electronics products is becoming shorter and shorter. The effective management and design of electronics assembly systems requires the development of complex integrated design and production planning support systems. To manage and control the electronics 
assembly line effectively as well as to reduce (a) the piling up of inventory, (b) major mismatches in capacities between different parts of the process, and (c) missed production targets, it is necessary to realistically control the systems and eliminate unexpected breakdowns of machines and systems.

\begin{tabular}{|c|c|}
\hline Today & Tomorrow \\
\hline 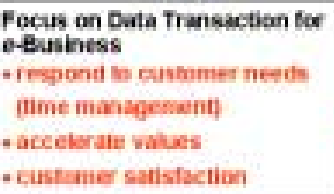 & 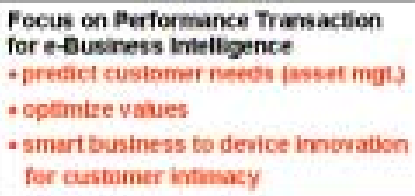 \\
\hline
\end{tabular}

Figure 2. Strategies in business innovation

As production systems are characterised by short production life cycle, high production diversity and customer demand for both excellent quality and timely delivery, it is necessary to monitor and control the automated manufacturing systems to obtain an optimised outcome. The e-intelligence will change the business pattern from on site service to remote/electronic service. Hence, there is a growing demand to connect the frontend business and back end business to synchronize the manufacturing system and product service and customer relationship. Innovative smart devices that predict product service and links it to its service supply chain and the required manufacturing plans are critical for this transformation. Figure 3 shows the needs on e-intelligence for business to device (B2D) is to bridge the gap between the front end and back end business.

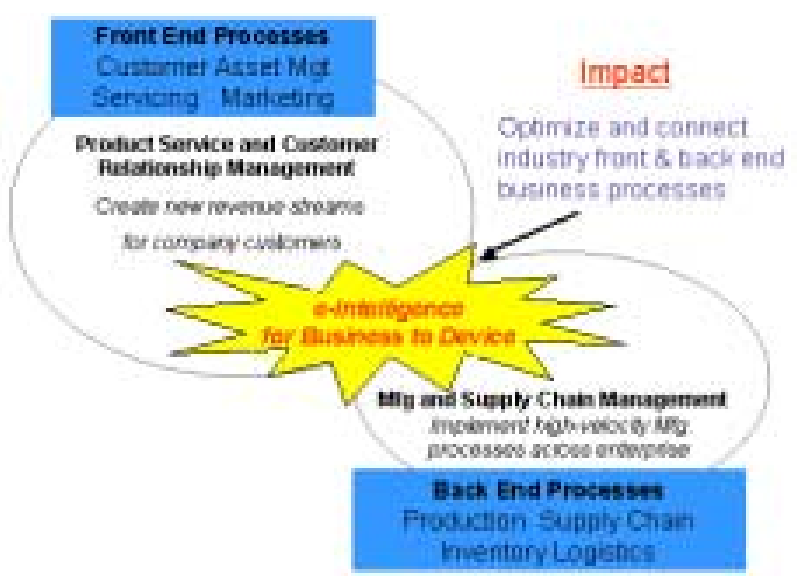

Figure 3. Impact of e-Intelligence for Business-to-Device

\section{FOCUS ON CUSTOMER SOLUTION AND SERVICE INNOVATION}

The value of strategic technologies that a company possesses is dependent on whether these technologies are making innovative business impacts. A new business model is required to focus on customer's solutions through product and service innovation. A focus on solution allows us to think about other than traditional ways of approaching a problem. Comprehensive solutions require an entire systems orientation, not just one component of a system. We must innovate our product service systems to provide our customers with better solutions. For example, a smart product software that can predict the failure of a system in advance. Such "prognostic" capability gives us an ability to provide a new kind of aftermarket service to guarantee highest and continuous performance of products, operations and all assets. As we think about solutions, we realize that a customer's need extends to the life of a product, and requires a system design that takes into account aftermarket support.

Currently, many manufacturing industries are performing service and maintenance activities still based on a reactive approach. The fundamental issue that prevents us from resolving these problems is an inadequate understanding of the behavior of product and manufacturing equipment on a daily basis. We simply do not know how to measure the performance degradation of components and machines. We lack the validated predictive models and tools that tell us what would happen when the process parameters decrease from values. Research and in depth investigation is required to understand the factors involved in product and machine degradation. Smart and reconfigurable monitoring tools should be developed to reduce or eliminate production downtime and reduce dimensional variation via predictive and preventive maintenance systems. In order to predict and prevent product failures, degradation (not defect or fault) of system components has to be detected in advance. In order to detect degradation, we plan to compare the actual working asset (machine, product, equipment or system) symptoms with (a) symptoms of an asset at its perfect condition, (b) symptoms of multiple assets of the same kind working on similar environment, (c) symptoms of a virtual asset model.

\section{PRODUCT PROGNOSTICS-WATCHDOG AGENT}

Remote and real time assessment of machine's performance information requires an integration of many different technologies including sensory devices, reasoning agents, wireless communication, virtual integration and interface platforms. A complete understanding and interpretation of states of degradation is necessary to accurately predict and prevent failure of a component or machine. When aging occurs, the component and machine generally progress through a series of degradation states before failure occurs. If a degradation condition can be measured and detected, then a proactive and corrective maintenance activities can be performed before a worse degradation condition or failures occur. In addition, product's performance degradation behavior is often associated with multi-symptom-domain information cluster, which consists of degradation behavior of functional components in a chain of actions. It is known that biological perceptual systems are often conceptualized as containing two stages of processing: an early stage de- 
tects individual stimulus features and a later stage combines the detected features into abstract representations that facilitate thought, decision making, or action. Drawing inspiration from this biological phenomenon, a neural network based multi-symptom-domains behavior assessment methodology has been developed by the Center. This approach, namely, a Machine Psychologybased watchdog agent has been pioneered by the author [8][9]. It uses behavior-based computation rather than a model-based computation, which often involves in using sophisticated machine condition information. To effectively apply this methodology in various kinds of products and machines, its integration with working environment (i.e. sensors, actuators, controllers, and human interfaces) need to be developed. A watchdog chip has been developed by the author to provide product degradation assessment and prognostics. In addition, this digital doctor can be connected with a telephone modem so that the behavior of products or machines and their performance information could be accessed and evaluated from a remote site. With the advent of the information, communications, digital signal processing (DSP), and system-on-a-chip technologies, intelligent maintenance and service tools (e.g. a head-mount IR-based prognostics device) with this smart watchdog agent would enable manufacturers and customers to rapidly assess product's performance and strategize required maintenance activities competitively. The watchdog agent and its working principle is shown in Figure 4.

Self-maintenance and recovery features should be considered for overall system improvement, and for determining what to do in case of product malfunctions. Under various conditions, the system should be able to operate and perform basic functions, in spite of deteriorated performance, and inform a remote agent for service support (e.g. a copy machine can adjust its roller speed autonomously to compensate slippage of papers and prevent them from jamming). The knowledge of machine performance can be learned and modeled eventually to be used in machine performance compensation. Thus, the performance of a typical machine may not necessarily degrade over time, but instead be improved by using the learning-modeling-compensation techniques. In addition, knowledge-intensive intelligent tools are required for the acquisition and organization of data in machine and its working environment to track the

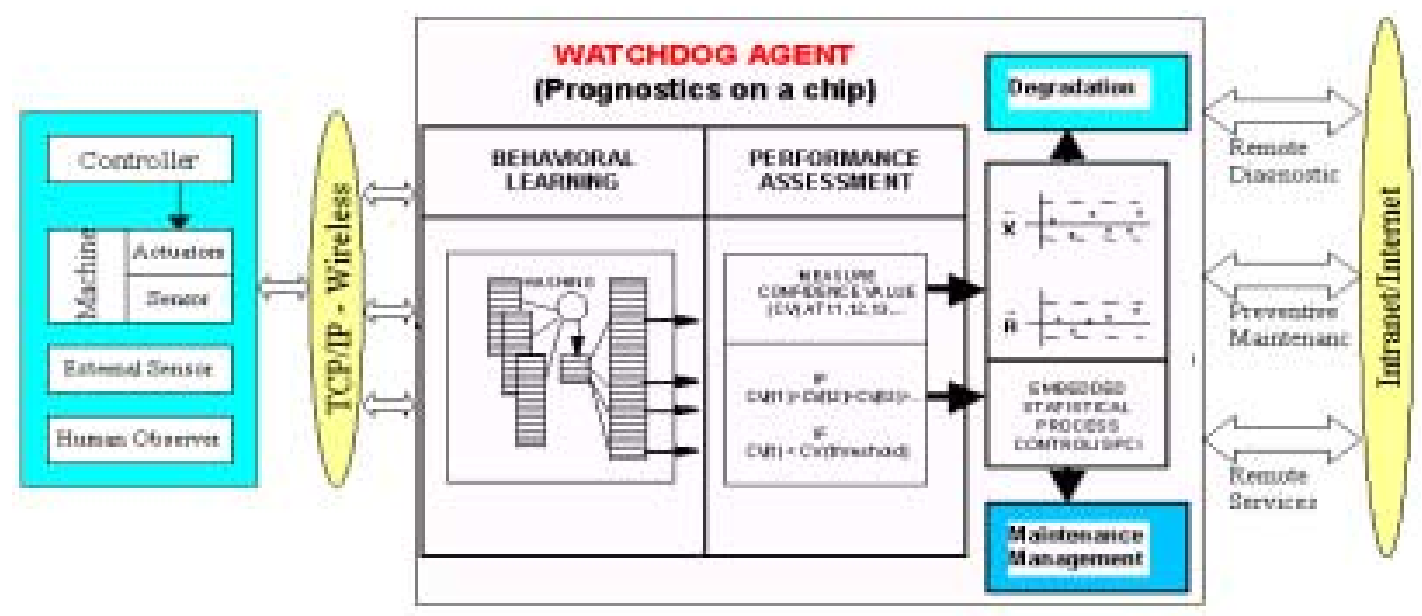

Figure 4. Smart Watchdog Agent for remote monitoring and control

behavior of machine at any given time. Even though the topics of supervised learning and self-learning have been studied by various researchers, they become more critical in a proactive maintenance environment. Due to the complexity of today's products and machines, process knowledge data from many different applications need to be correlated for autonomous performance assessment. A watchdog agent could also serve as a "blackbox" of a machine and is able to keep the signatures of major components. In case of failure, operators can access the "blackbox" and obtain the last several minutes of information about the behavior of machine. As a result, faults can be located quickly and system can be recovered rapidly. This knowledge-based information also can be shared with other user. Reconfigurability and transferability are also important aspects of the system development.
Due to the fast change of the computer/internet technologies, the developed system will incorporate these advancements easily without major modifications.

To achieve a just-in-time lean maintenance and service operation, better decision making tools are required to strategize resources through a supply-chain network system. Currently, many commercially available maintenance management software tools lack integratability with production control systems as well as lack value in managing maintenance logistics and service business. Companies need to perform remote maintenance decision making to support technical and business personnel in manage maintenance and service logistics activities. In addition, digital service modem can be used to integrate product's performance conditions with the customer support center via Internet. 


\section{FUTURE TREND IN E-MANUFACTURING, E- MAINTENANCE AND E-BUSINESS}

Customers in today's continuously changing and everchallenging market are demanding more customized products, faster delivery, and instant access to their order status. They also select the products not only based on their brand names and sale cost, but also based on its reliability, dependability, service options, in turn, based on its value in a long if not life term. Internet, web enabled and wireless technologies help customers to have more and more options in front of them at an instant of a click. Their access to more suppliers and products through Internet unlimits their power of purchase, and empower them to ask better products at a minimum cost with extended service additions. E-business has been evolved to satisfy such needs of customers. However, ebusiness without a profound manufacturing support lacks delivering what customers are asking. Manufacturers will need to increase their response and production speed, and provide visibility of products, production, and process across the whole supply chain starting and ending with the customer.

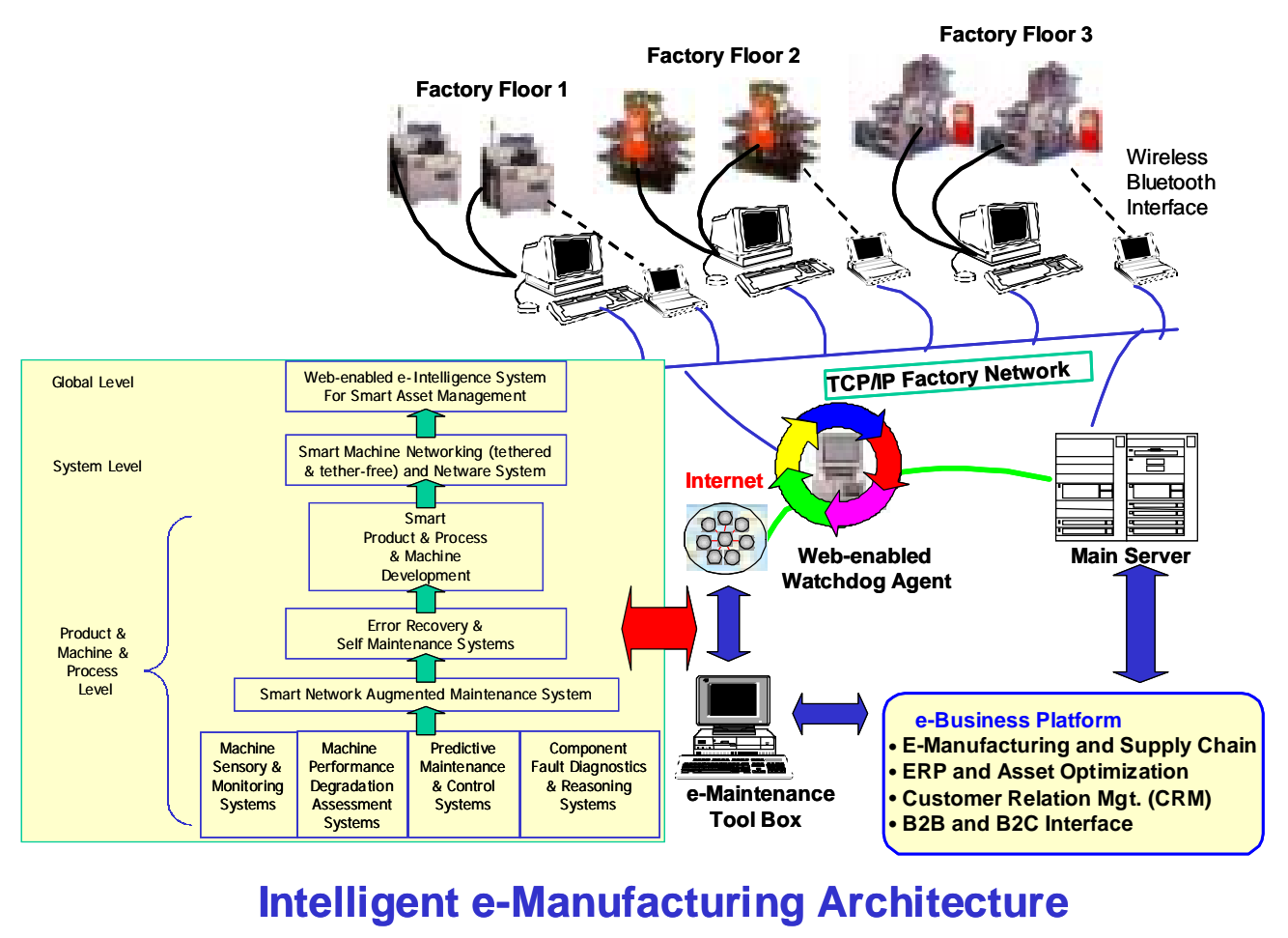

Figure 5. Intelligent e-Manufacturing architecture

Lead times of products need to be decreased tremendously. A company's capability to answer customer orders and bring about solutions to their needs primarily depends on their production speed, not their warehouse capacity, or their quickness to accept and process the orders. Because of this, lately many companies started outsourcing their production units to focus on marketing side of the business so that they can satisfy their customers. However, this is not an ultimate solution as they are still dependent on the production capabilities and responsiveness of their suppliers. If these suppliers can not find a solution and improve their production speed, at the end customers will move to another option that they can easily access through today's global, open and web based market.

Existing solution systems such as Enterprise Resource Planning (ERP) and Supply Chain Management (SCM) software could not provide the real-time production control capabilities necessary to make good use of information available. In order to succeed the new economy pace and be part of e-business solution, manufacturers need a comprehensive solution. A solution that (a) connects customers to the plant floor in real-time, (b) provides visibility, and (c) empowers plant floor operators perform proactive measures with reliability, dependability and a common platform for all operations, plants, etc. Real-time access of information at various and remote locations would increase the overall efficiency. Every single member of chain- suppliers, distributors, logistic and technology providers, manufacturers at all levelsshould possess the capability, willingness and technology to implement the elements of e-manufacturing. It should include intelligent maintenance and performance assessment systems to provide reliability, dependability and minimum downtime with equipment running smoothly at their highest performance. Figure 5 illustrates the bone concept of e-maintenance and its position with in the e-manufacturing and e-business problem. 


\section{CONCLUSIONS}

Tomorrow's manufacturing industries must cope with the life cycle support of the products in a globalized enterprise. Information technology will play an indispensable role in supporting and enabling the complex practices of design and manufacturing by providing the mechanisms to facilitate and manage the integrated system discipline. The need to improve the understanding of product's performance for aftermarket service will lead to advanced maintenance and service technology for other reasons than troubleshooting. With the proper integration of e-intelligence into products and manufacturing systems, manufacturers and users will benefit from the increased equipment and process reliability.

\section{REFERENCES}

Welch J. \& GE. Business Week, Oct. Issue, 1996.

Telematics to the Rescue, IEEE Spectrum, Jan. pp 93, 2001.

Schroeder, K. Interviews with Investor's Business Daily, CEO of KLA-Tencor Corp., August, 2000.

Lee, J. Machine Performance Assessment Methodology and Advanced Service Technologies. Report of Fourth Annual Symposium on Frontiers of Engineering, National Academy Press, pp.75-83, Washington, DC, 1999.
Lee, J. \& B. Wang. Computer-aided Maintenance: methodologies and practices, Kluwer Academic Publishing, 1999.

Department of Commerce Data, Nov. 1999.

National Research Council. The Competitiveness Edge: Research Priorities for U.S. Manufacturing, National Academy Press, 1990.

Lee, J. and B. M. Kramer. Analysis of Machine Degradation using a Neural Networks Based Pattern Discrimination Model, J. Manufacturing Systems, Vol. 12, No. 3, pp. 379-387, 1992.

Shi, J., J. Ni \& J. Lee. "Research Challenges and Opportunities in Remote Diagnostics and System Performance Assessment," Proceeding of 4th IFAC Workshop on Intelligent Manufacturing Systems: IMS'97, July 21-23, Seoul, Korea, 1997.

Lee, J. "Teleservice Engineering in Manufacturing: Challenges and Opportunities, International Journal of Machine Tools \& Manufacture, vol. 38, pp. 901910, 1998.

Botkin, J. Smart Business, The Free Press, 1999.

Kurzweil, R. The Age of Spiritual Machine, Penguin Books, 1999.

Charan, R. \& Tichy, N. Every Business is a Growth Business, Times Business, 1998. 